\title{
Dead space ventilation parallels changes in scintigraphic vascular obstruction at recurrence of pulmonary embolism and after thrombolytic therapy: A case report
}

Marc A Rodger MD, Gwynne Jones MD, Francois Raymond MD, Daniel Lalonde MD,
Mike Proulx RRT, Lothar Huebsch MD, Christopher Bredeson MD
Ottawa General Hospital, University of Ottawa, Ottawa, Ontario

MA Rodger, G Jones, F Raymond, D Lalonde, M Proulx, L Huebsch, C Bredeson. Dead space ventilation parallels changes in scintigraphic vascular obstruction at recurrence of pulmonary embolism and after thrombolytic therapy: A case report. Can Respir J 1998;5(3):215-218.

Physiological and alveolar dead space ventilation both increase in pulmonary embolism (PE) in proportion to the severity of vascular obstruction. The case of a patient with recurrent PE while on heparin therapy is presented. The recurrence was characterized clinically by severe pulmonary vascular obstruction and right heart dysfunction. The patient was treated with thrombolytic therapy, with excellent clinical and scintigraphic resolution. Dead space ventilation measurements at baseline, at the time of recurrence and after thrombolytic therapy are presented. The potential utility of dead space ventilation measurements for PE diagnosis and management are discussed.

Key Words: Alveolar dead space, Physiological dead space, Pulmonary embolism, Thrombolytic therapy
La ventilation de l'espace mort est parallèle aux changements dans l'obstruction vasculaire observée à la scintigraphie lors d'embolies pulmonaires récidivantes et après un traitement thrombolytique : une étude de cas

RÉSUMÉ: La ventilation de l'espace mort alvéolaire et celle de l'espace mort physiologique s'accroissent toutes deux en présence d'une embolie pulmonaire (EP) et sont proportionnelles à la gravité de l'obstruction vasculaire. Le cas d'un patient accusant des EP récidivantes tout en étant héparinisé est présenté. Sur le plan clinique, la récidive s'est caractérisée par une grave obstruction des vaisseaux pulmonaires et un dysfonctionnement du cœur droit. Le patient a reçu un traitement thrombolytique qui a entraîné une excellente résolution des embolies à la fois clinique et démontrée à la scintigraphie. Les mesures de la ventilation de l'espace mort au point de référence, ainsi qu'au moment de la récidive et après le traitement thrombolytique sont présentées. L'utilité potentielle des mesures de la ventilation de l'espace mort pour poser un diagnostic d'embolie pulmonaire et pour sa prise en charge sont discutées. 
D ead space ventilation represents ventilation of parts of the lung not involved in gas exchange. Physiological dead space ventilation is the sum of two components: anatomical dead space ventilation and alveolar dead space ventilation. Anatomical dead space ventilation represents ventilation of the airways. Alveolar dead space ventilation represents ventilation of alveoli that are not involved in gas exchange. In pulmonary embolism (PE), thrombus occludes part of the pulmonary arterial tree resulting in unperfused alveoli. These unperfused alveoli may be ventilated, resulting in an increase in alveolar dead space ventilation. Interest has been generated in the literature in examining measures of alveolar dead space ventilation as clinical predictors of PE (1-7).

We describe a case of PE where sequential dead space ventilation measurements correlated with clinical and scintigraphic recurrence of $\mathrm{PE}$ and subsequent resolution after thrombolysis.

\section{PATIENT AND METHODS}

Dead space ventilation measurements: The sitting patient breathed through a Hans Rudolph one-way valve (Hans Rudolph, Missouri) with the expiratory side of the valve connected via a three way stopcock to a 60 L Douglas bag (PK Morgan, Rainham United Kingdom). Once the patient was judged to be relaxed and breathing regularly by the respiratory therapist, expired gas was collected for a timed period of 3 mins. A sidestream port on the Hans Rudolph valve provided continuous breath by breath expired carbon dioxide data (measured by a Datex capnograph, datex Engstrom, Finland). Arterial puncture was performed for arterial blood gas analysis at the end of the 3 min collection. The expired gas collected in the Douglas bag was analyzed for carbon dioxide concentration $\left(\mathrm{PeCO}_{2}\right)$ using a blood gas analyzer (CIBA Corning 278, Chiron diagnostics, Maryland). The arterial blood gas was analysed for $\mathrm{pH}$, concentration of carbon dioxide in arterial blood gas $\left(\mathrm{PaCO}_{2}\right)$ and concentration of oxygen in arterial blood gas $\left(\mathrm{PaO}_{2}\right)$ using the same blood gas analyser.

Physiological dead space (VD/VT) was calculated using the Bohr equation (1):

$$
\mathrm{VD} / \mathrm{VT}=\left(\mathrm{PaCO}_{2}-\mathrm{PeCO}_{2}\right) / \mathrm{PaCO}_{2}
$$

The average end-tidal carbon dioxide of the last 10 breaths before the end of the 3 min collection of expired gas was recorded $\left(\mathrm{PEtCO}_{2}\right)$. The alveolar dead space fraction (AVDSf) was calculated as follows (2).

$$
\text { AVDSf }=\left(\mathrm{PaCO}_{2}-\mathrm{PEtCO}_{2}\right) / \mathrm{PaCO}_{2}
$$

Pulmonary vascular obstruction score: Ventilation and perfusion scans were obtained. Two nuclear medicine physicians interpreted scintigrams independently and blindly. Pulmonary vascular obstruction (PVO) score was assigned by the method of Brochier et al (8).

\section{CASE PRESENTATION}

A 62-year-old man presented with sudden worsening dyspnea and epigastric pain on the day of presentation. In the week before admission he had experienced stepwise progressive dvspnea and episodic epigastric pain. One month before
TABLE 1

Serial pulmonary vascular obstruction scores, physiological dead space measurement and alveolar dead space measurement at pulmonary embolism (PE) diagnosis, recurrence and after thrombolysis in a 62-year-old man

\begin{tabular}{lccc}
\hline Event & $\begin{array}{c}\text { Pulmonary } \\
\text { vascular } \\
\text { obstruction } \\
\text { score }\end{array}$ & $\begin{array}{c}\text { Physiological } \\
\text { dead space } \\
(\%)\end{array}$ & $\begin{array}{c}\text { Alveolar } \\
\text { dead } \\
\text { space } \\
\text { fraction }\end{array}$ \\
\hline PE at presentation & 0.71 & 42 & 0.23 \\
PE recurrence & 0.60 & 50 & 0.31 \\
After thrombolysis & 0.89 & 23 & $\mathbf{0 . 0 0}$ \\
\hline
\end{tabular}

admission he had experienced onset left thigh and calf tenderness and leg swelling. He had no cough, phlegm, hemoptysis, fever, chills, sweats or chest pain in the week before admission.

The patient had had a right lower lobectomy for bronchiectasis 30 years earlier. He had no other history of heart or lung disease. He had a 20-pack year smoking history but had stopped smoking 30 years before. He had no prior history, no family history and no other risk factors for venous thromboembolism. He was on no medications.

On examination he was in no respiratory distress. Heart rate was 132 beats/min, respiratory rate 18 breaths/min, blood pressure $136 / 96 \mathrm{mmHg}$ and temperature $37.6^{\circ} \mathrm{C}$. Respiratory examination revealed a scar from his previous lobectomy and decreased air entry to the right base. There were no adventitial sounds. Cardiovascular examination revealed a normal jugular venous pressure (JVP) at $2 \mathrm{~cm}$ above the sternal angle and normal heart sounds. He had tenderness along the deep veins of the calf and thigh as well as pitting edema of his left leg.

A posteroanterior and lateral chest x-rays demonstrated an opacity at the right base consistent with a small right pleural effusion. An electrocardiogram revealed sinus tachycardia with diffuse nonspecific ST-T abnormalities. Compression ultrasound demonstrated a deep vein thrombosis of the superficial femoral vein. Ventilation-perfusion (V/Q) scan revealed multiple, moderate subsegmental perfusion defects with normal ventilation in both lungs (Figure 1), interpreted as high probability for PE.

VD/VT and AVDSf were measured at the bedside after informed consent was obtained. AVDSf was 0.23, and VD/VT was $42.9 \%$ (Table 1). The mean PVO score at presentation was 0.71 (ie, $71 \%$ of his lung was perfused) (Figure $1)$.

The patient was admitted to hospital and treated with intravenous unfractionated heparin. On day 4, while fully anticoagulated (heparin assay by modified thrombin time $=0.23$, therapeutic range 0.2 to 0.4 ), he developed sudden recurrence of dyspnea and epigastric discomfort. Physical examination revealed evidence of right heart dysfunction with a JVP at $5 \mathrm{~cm}$, a Kussmaul's sign and positive hepatojugular reflux. His electrocardiogram and chest x-ray were un- 

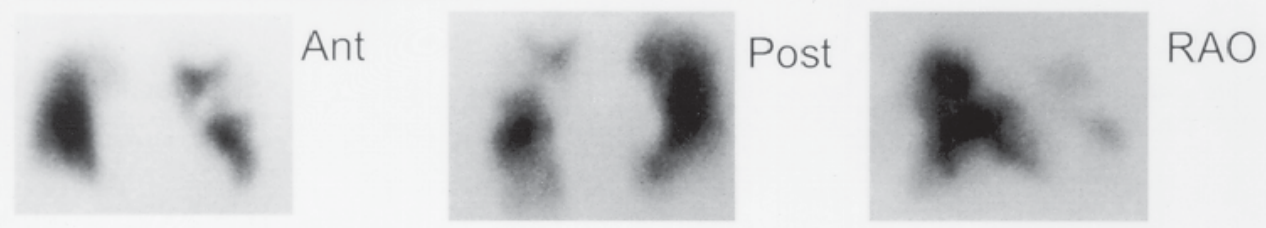

At Recurrence: 3 Oct.
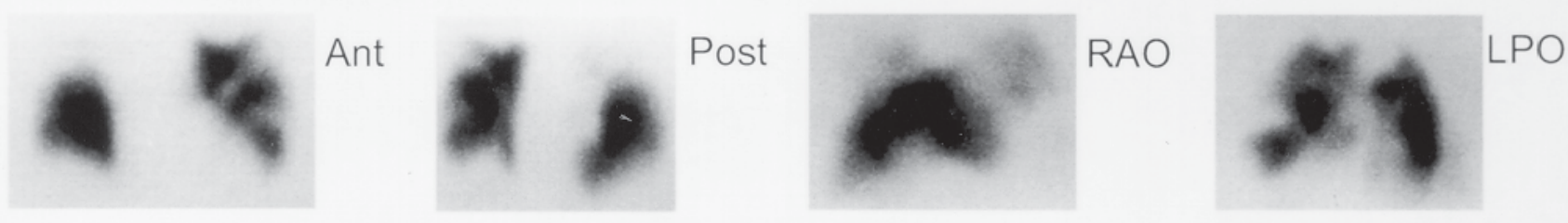

\section{After Thrombolysis: 7 Oct.}
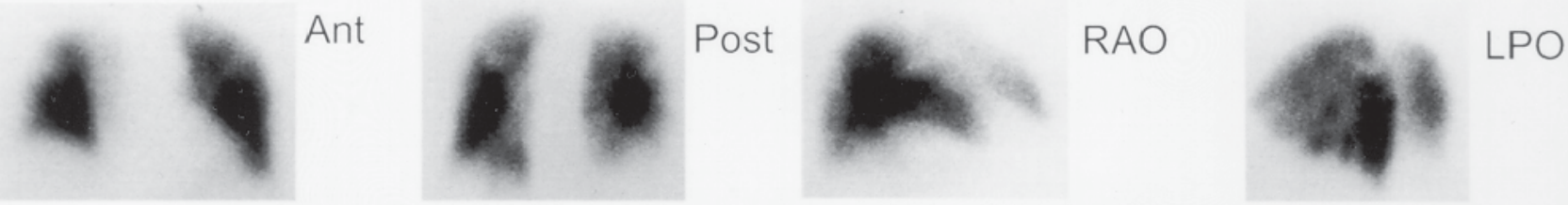

Figure 1) Perfusion scans obtained at presentation, at time of recurrence and after thombolysis. Ant Anterior view; LPO Left posterior oblique view; Post Posterior view; RAO Right anterior view

mental perfusion defect involving his right upper lobe. PVO score had decreased to 0.60 (Figure 1), AVDSf had increased to 0.31 and VD/VT had increased to $50 \%$ (Table 1 ). Streptokinase was administered with a bolus of 250,000 $\mathrm{U}$ followed by $100,000 \mathrm{U} / \mathrm{hfor} 24 \mathrm{~h}$. At the conclusion of thrombolytic therapy, the patient's subjective assessment of dyspnea had markedly improved, the epigastric discomfort had resolved, and JVP had returned to normal. The same day a repeat V/Q scan showed near complete resolution of the perfusion defects. His PVO score had improved to 0.89 (Figure 1), AVDSf had improved to zero, and VD/VT decreased to $23.4 \%$ (Table 1).

\section{DISCUSSION}

This case demonstrated that sequential measures of physiological and alveolar dead space can parallel clinical and scintigraphic evidence of PE recurrence and subsequent successful thrombolysis. Physiological and alveolar dead space can be measured at the bedside in a minimally invasive method requiring 15 to 20 mins. The equipment necessary (a capnograph, a Douglas bag and a Hans Rudolf valve) is relatively inexpensive and could be made widely available. Burki (1) has suggested a normal cutoff for VD/VT of $40 \%$. Kline et al (7) reported a normal cutoff for AVDSf of 0.2 . Both AVDSf and VD/VT may increase in other disease states including chronic obstructive lung disease and other pulmonary vascular conditions $(1,2)$. Physiological factors may influence VD/VT including posture, lung volume and ventilatory pattern. VD/VT should only be measured under steady state conditions (ie, in a patient with stable respiratory rate and end-tidal carbon dioxide) (2). Despite these concerns, our experience demonstrates that, if care is taken to ensure that these measurements are conducted on a patient with a stable respiratory rate and end-tidal carbon dioxide and who is sitting, good interuser reliability and reproducibility are achievable (unpublished data).

This case generates several hypotheses about the potential clinical utility of dead space measurements in PE management. First, measures of dead space ventilation may be useful in determining which PE patients will benefit from thrombolytics. Measures of dead space ventilation appear to correlate with scintigraphic severity of vascular obstruction after PE (9). Scintigraphic obstruction greater than $30 \%$ is thought to be associated with a higher risk of recurrent PE and death from recurrence $(10,11)$. Goldhaber et al (11) suggest that patients with large perfusion deficits should be considered for thrombolytics. Riedel et al's study (12) suggests that patients who die of PE during long-term follow-up have higher VD/VT at time of PE diagnosis than those who survive long term. The identification of PE who derive clinically meaningful benefit from thrombolytic therapy remains problematic. Several studies have shown that PE patients treated with thrombolytics, compared with patients treated with standard heparin, have superior resolution of hemodynamic and lung scan abnormalities (13). No study, however, has demonstrated a clear mortality benefit with thrombolytic therapy over standard heparin therapy (13). The current recommendation is that thrombolytics be considered in patients with 
acute massive embolism who are hemodynamically unstable and have no major bleeding risk (14). Measures of dead space ventilation could be used to identify a broader subgroup of PE patients with a large burden of thrombus who would derive clinically meaningful benefit from thrombolytic therapy. Further study is required to determine whether this is the case. Second, serial dead space measurements may be useful in determining the adequacy of thrombolysis and, hence, they may be used to decide when thrombolytics should be stopped. Prediletto et al (9) have shown that dead space measurements correlate well with scintigraphic resolution of PE. Given the simplicity, minimal discomfort and bedside nature of dead space measurement this analytical method appears to be a potentially ideal tool for monitoring response to therapy and assessing adequacy of thrombolysis. Finally, as illustrated by this case, serial dead space measurements may be useful in the diagnosis of suspected PE recurrence.

In conclusion, measurements of dead space ventilation may prove useful in the diagnosis of recurrent pulmonary embolism, identifying subgroups of high risk PE patients and monitoring response of PE to thrombolytic therapy.

\section{REFERENCES}

1. Burki NK. The dead space to tidal volume ratio in the diagnosis of pulmonary embolism. Am Rev Respir Dis 1986;133:679-85.

2. Erikson L, Wollmer P, Olsson C, et al. Diagnosis of pulmonary embolism based on alveolar dead space analysis. Chest 1989;96:357-62.
3. Robin ED, Julian D, Travis D, et al. A physiologic approach to the diagnosis of acute pulmonary embolism. N Engl J Med 1959;260:586-91

4. Nutter DO, Massumi RA. The arterial-alveolar carbon dioxide tension gradient in diagnosis of pulmonary embolus. Dis Chest 1966;50:380-7.

5. Hatle L, Rokseth R. The arterial to end-expiratory carbon dioxide tension gradient in acute pulmonary embolism and other cardiopulmonary diseases. Chest 1974;66:352-7.

6. Grosbois JM, Bart F, Douay B, et al. Intérêt de la concentration expiratoire maximale de $\mathrm{CO}_{2}\left(\mathrm{CEM} \mathrm{CO}_{2}\right)$ pour le diagnostic négatif de l'embolie pulmonaire aiguë au cours de bronchopneumonie chroniques obstructives. Rev Mal Respir 1995;12:35-41.

7. Kline JA, Meek S, Boudrow D, Warner D, Colucciello S. Use of the alveolar dead space fraction and plasma d-dimers to exclude acute pulmonary embolism in ambulatory patients. Acad Emerg Med 1997;4:856-63.

8. Brochier M, Raynaud P, Fauchier JP, et al. Comparison between lung scans and pulmonary angiograms in the evaluation of the perfusion defect in massive and submassive pulmonary embolism. In: Widimsky J, ed. Pulmonary Embolism. Progress in Respiration Research. Basel: Karger, 1980;120-6.

9. Prediletto R, Paoletti P, Fornai E, et al. Natural course of treated pulmonary embolism. Chest 1990;97:554-61.

10. Goldhaber SZ, Haire WD, Feldstein MJ, et al. Alteplase versus heparin in acute pulmonary embolism: randomised trial assessing righ-ventricular function and pulmonary perfusion. Lancet 1993;341:507-11.

11. Goldhaber SZ. Thrombolytic therapy in venous thromboembolism Clinical trials and current indications. Clin Chest Med 1995;16:307-20.

12. Riedel M, Stanek V, Widimsky J, Prerovsky I. Longterm follow-up of patients with pulmonary thromboembolism. Late prognosis and evolution of hemodynamic and respiratory data. Chest 1982;81:151-8.

13. Anderson DR, Levine MN. Thrombolytic therapy for the treatment of acute pulmonary embolism. Can Med Assoc J 1992;146:1317-21.

14. Hyers TM, Hull RD, Weg JC. Antithrombotic therapy for venous thromboembolic disease. Chest 1995;108(Suppl):335S-50S. 


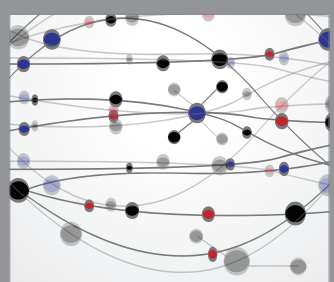

The Scientific World Journal


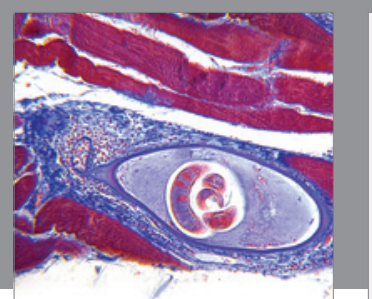

Gastroenterology Research and Practice

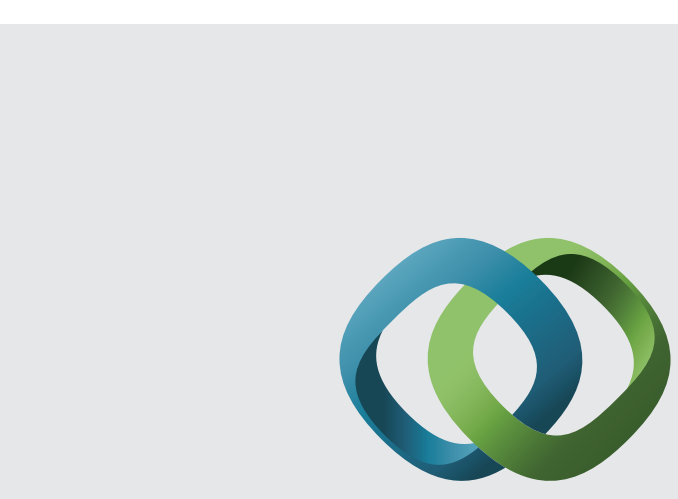

\section{Hindawi}

Submit your manuscripts at

http://www.hindawi.com
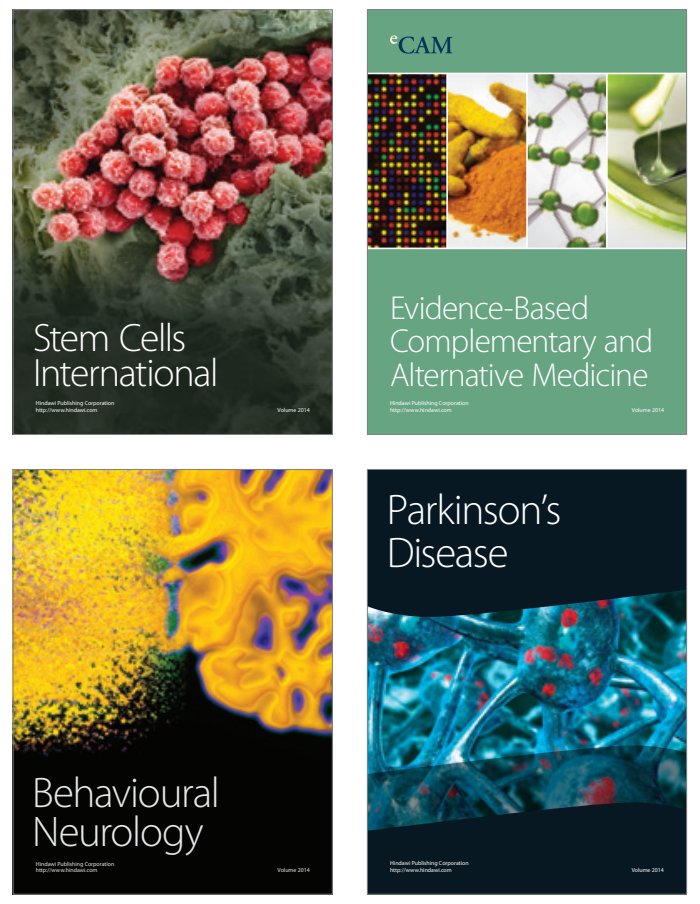
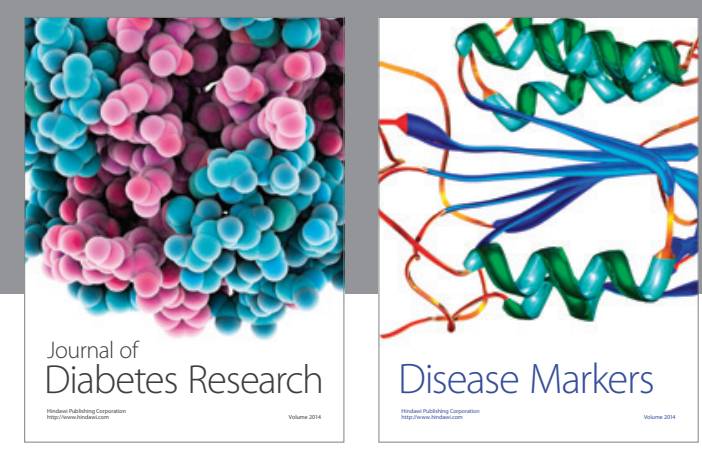

Disease Markers
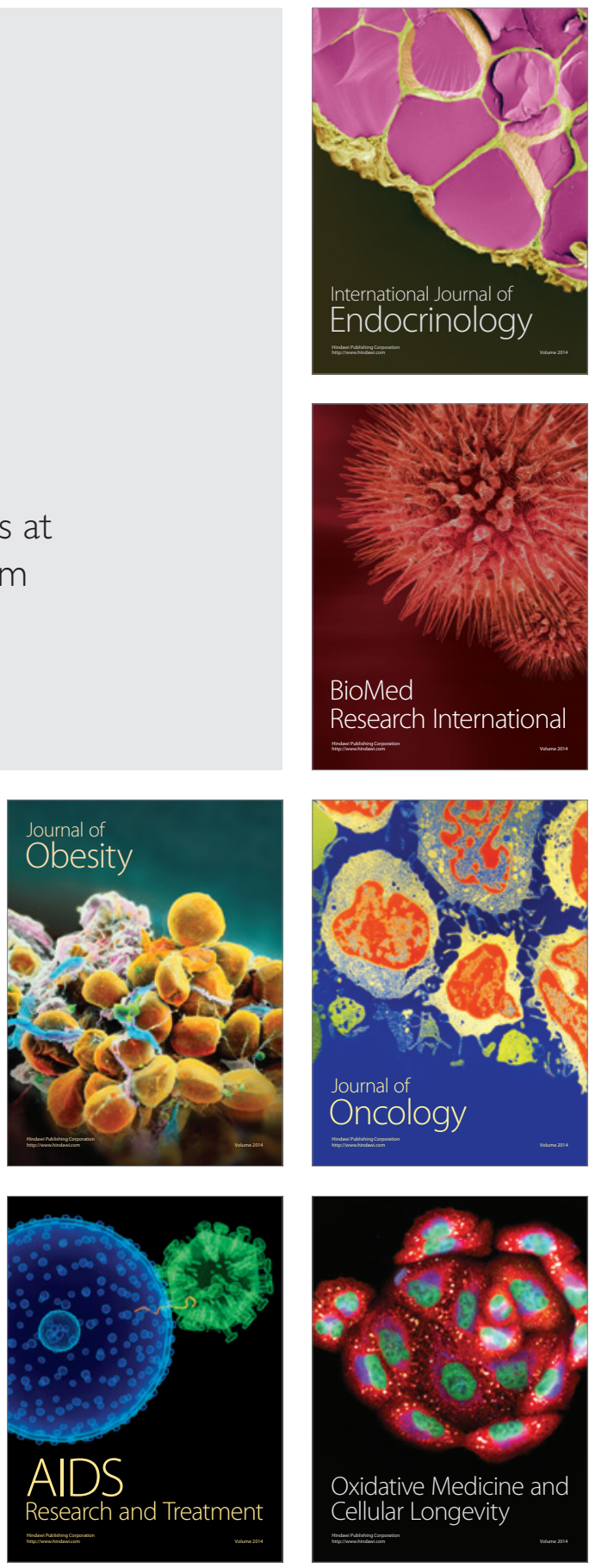